Aim of the study: The purpose of this study is to investigate the complementary/alternative medicine (CAM) usage and the factors affecting this among cancer patients in the western region of Turkey. 220 adult cancer patients participated in the study and 93 patients $(42.3 \%)$ were found to use at least one CAM method.

Material and methods: Our study was done by face-to-face communication in a university hospital, in Turkey. Oncology patients' primary diseases, sociodemographic characteristics, complementary alternative medicine usage, psychological conditions and quality of life were evaluated with proper psychological scales. Patients using and not using CAM were compared with respect to Beck Depression, State Trait Anxiety and Beck Hopelessness scores. No statistically significant difference was detected between/among the groups in BDI $(12.0 \pm 8.4,11.9 \pm 8.7, p=0.96)$, BHS $(5.5 \pm 4.9,4.8 \pm 4.4, p=0.27)$ or STAI $(43.7 \pm 8.0,44.3 \pm 8.2, p=0.64)$ scores. Patients using and not using CAM were compared with respect to WHOQOLBREF quality of life scores. There was no statistically significant difference between/among the groups in WHOQOLBREF sub-group scores (physical, psychological, social relations, environment, standardized by culture (environment), general health).

Results: Nearly half of the patients $(42.3 \%)$ in this region were found to be using at least one of the CAM methods. The patients mostly preferred herbal methods, with the leading product being stinging nettle (Urtica dioica). The severity of disease (recurrence and dissemination) and patients' knowledge of the diagnoses were the most important factors affecting the CAM usage.

Conclusions: The usage of CAM by oncology patients and the effects of CAM on the present medication prescribed by oncology practitioners must be remembered when they are admitted to polyclinics. Also it must be known that patients with advanced stage and patients with recurrence are more likely to use complementary alternative medications than early stage patients. Therefore oncology patients must be informed about CAM besides their clinical situations. At least physicians should give answers about the CAM to their patients.

Key words: complementary/alternative medicine (CAM), depression, anxiety, quality of life, cancer patients.

\section{The association of complementary alternative medicine use with anxiety, depression and quality of life in Turkish cancer patients}

\author{
Oktay Tarhan ${ }^{1}$, Ahmet Alacacioglu', Isil Somali', Hilal Sipahi ${ }^{3}$, \\ Mehmet Zencir ${ }^{4}$, Cigdem Erten ${ }^{1}$, Meliha Dirioz ${ }^{5}$, Ilhan Oztop ${ }^{5}$, \\ Mehmet Ozgur Niflioglu', Ugur Yilmaz
}

${ }^{1}$ Ataturk Training and Research Hospital, Medical Oncology, Izmir, Turkey 2lzmir Training and Research Hospital, Medical Oncology, Izmir, Turkey ${ }^{3}$ Ege University, Faculty of Medicine, Public Health, Izmir, Turkey 4Pamukkale University, Faculty of Medicine, Public Health, Denizli, Turkey ${ }^{5}$ Dokuz Eylul University, Institute of Oncology, Izmir, Turkey

Complementary-alternative medicine (CAM) is a wide healthcare field that includes all the health systems, methods, practices and the concomitant theories and beliefs aside from the politically dominant health system in a certain community or culture within a certain period of time [1]. While CAM is known as a concept against modern medicine until recent years, it is currently considered as a method that supplements modern medicine and is put into use occasionally when modern medicine is inadequate.

The motivators of people in using or administering CAM are not well established [2]. Important motivators include deficiencies or irregularities in standard health services, inclination towards CAM due to habits, preference for "usual" or "natural" treatment modalities and the fact that patients' health issues are chronic [3-8].

In Western countries, the interest in and inclination towards CAM have been gradually increasing recently. The reasons for the current popularity of CAM use are quite complex [9] and are associated with the socio-cultural structure [7]. The severity of the disease was detected to be a strong factor in CAM use by patients [9]. CAM use is higher in cancer patients with advanced disease or poor prognosis (or both) [10-13]. In a "survey" study performed in the 1990s in cancer patients, CAM therapies were observed to be used commonly worldwide [2]. The prevalence of CAM use in cancer patients ranges between $7 \%$ and $72 \%$ in 26 trials performed in 13 countries (4 trials in the paediatric group) $[3,5]$. Although there are no reliable statistical data on CAM use in our country, it is considered to be used commonly. This rate ranges between $23 \%$ and $61 \%$ in the trials reported [11, 15-17].

In some observations, recurrence or re-recurrence triggers initiation of CAM [18]. However, many patients research CAM methods also in the diagnosis period. The uncertainty in the success of conventional treatment influences patients to try CAM. For a portion of patients, the CAM process is simply considered to participate in improvement [19]. In addition, CAM use was determined to be closely related to the patient's psychological status. Burstein et al. [3] detected a correlation between the new CAM use (or administration) and depression, reduction in sexual satisfaction, the extent of fear of recurrence and somatic symptoms (480 patients were evaluated in this trial and the CAM rate was detected as 28.1\%). The 12-month observation revealed no significant difference between the groups using and not using CAM except the results on interest in and fear of sex. Investigators rec- 
ommended that clinicians should be careful about the fact that anxiety, depression and physical symptoms may be effective at the start of CAM use.

In the current trial, the effect of psycho-social status and quality of life of patients on CAM use was investigated in adult cancer patients treated at our hospital.

\section{Material and methods}

220 adult patients with solid cancer presenting to Dokuz Eylul University Medical Faculty Oncology who agreed to participate in the trial were enrolled. All patients gave written informed consent. A descriptive form was administered to patients, which included questions on demographic characteristics, patient characteristics and status of CAM use, time of initiation, decision to start treatment, reason for using this treatment, type of treatment, benefits, and recommendation to others.

In addition to these forms, the State Trait Anxiety Inventory (STAI), Beck Depression Inventory (BDI), BECK Hopelessness Scale (BHS) to assess the psychological status of patients and the WHOQOL-BREF Scale to assess the quality of life were used. Surveys including these scales were administered face to face.

\section{State Trait Anxiety Inventory (STAI)}

It is a 20-item scale. Patients are asked to choose one of the responses "none", "a little", "much", or "completely" according to the severity grade of the perception, thoughts or behaviours the patient expresses. There are straight or reversed expressions in scoring of the scale. While scoring the "reversed" expressions reflecting favourable feelings, those with a weighted value of 1 are converted to 4 and those with a weighted value of 4 are converted to 1 . For direct expressions reflecting unfavourable feelings, responses with a value of 4 indicate low anxiety while those with a value of 1 indicate high anxiety. There are 10 reversed expressions in the scale $(1,2,5,8,10,11,15,16,19,20)$. The obtained score ranges between 20 and 80 . A high score indicates a high level of anxiety while a low score indicates a low level of anxiety [20].

\section{Beck Depression Inventory (BDI)}

The differentiation of depression and other psychopathological conditions by depression level is targeted. It measures the somatic, emotional, cognitive and motivational signs observed in depression. The scale aims not to establish a diagnosis of depression but objectively determine the grade of depression signs. The form has 21 sign categories, each consisting of 4 choices. The patient is asked to mark the expression that best reflects how the patient has felt within the last week including the administration day. Each item is scored between 0 and 3. The depression score is obtained by adding these scores. The highest obtainable score is 63 . A high total score indicates a high level of depression or high severity of it [21].

\section{Beck Hopelessness Scale (BHS)}

It measures the unfavourable expectations of the individual for the future. It consists of 20 items. The items on feelings about the future were determined as 1, 6, 9, 13, 15; items on loss of motivation as 2, 3, 9, 11, 12, 16, 17, 20; and items on future expectations as 4, 7, 14, 18. As per scale keys including eleven "correct" and nine "incorrect" responses, each concordant response is scored " 1 " while each "discordant" response is scored "0". The "arithmetic" total obtained represents the total "desperation" score. When the scores, which may vary between 0 and 20, are high, the level of desperation is considered high [21, 22]. For the above-mentioned 3 psychological scales, the validity and safety tests have been performed for the people in our country [20-23].

\section{WHOQOL-BREF quality of life scale}

The studies conducted by the World Health Organization (WHO) yielded WHOQOL-100 and WHOQOL-BREF to evaluate the quality of life. Both scales were developed so as to enable inter-cultural comparisons. WHOQOL-100 includes 100 questions, 24 sections and 6 fields. WHOQOL-BREF includes 26 questions and four fields selected among WHOQOL-100 items (physical, psychological, social relations, environment and general health). The questions included in the scale are answered considering the last 15 days and contain Likert-type closed responses [24]. The questions are as follows: general health and quality of life, 1 and 2; physical health, 3, 4, 10, 15, 16, 17, 18; psychological health, 5, 6, 7, 11, 19, 26; social, 20, 21, 22; environment, 8, 9, 12, 13, 14, 23, 24, 25 (the $27^{\text {th }}$ question was added to the questions on environment for environment standardized by culture). Since questions $3,4,26$ and 27 are negative, a correction procedure was applied to calculate the score in the same way as the positive questions. All the other questions are positive [25]. The WHOQOL-BREF scale with validity and safety in Turkey evaluated by Fidaner et al. was considered to possess psychometric properties and found appropriate for clinical practice. By adding one more question on cultural characteristics for our country, the field of environment was separately evaluated in a manner standardized by culture [25].

The World Health Organization Quality of Life (WHO-QoL) instrument was developed by WHO. It assesses the individual's perceptions in the context of their culture and value systems, and their personal goals, standards and concerns. It was found suitable for clinical usage beside its competency for evaluating psychometric conditions. The WHOQOL-BREF instrument's reliability and validity have been widely tested in Turkey. That is why we prefer this instrument for evaluating cancer patients' quality of life.

\section{Statistical methods}

The program SPSS version 10.0 was used for data analysis. The relation between the categorical variables and KAT use was evaluated by chi-square analysis and the comparison between CAM use status and the scores obtained from the scales was performed by t-test. For statistical evaluation, the significance level was considered to be $p<0.05$.

\section{Results}

In this trial, 220 adult patients (79 male and 141 female) with solid cancer were evaluated. The mean age was 56.5 
(24-83). The patients had various cancers, with breast cancer (35.9\%) being most frequent followed by colorectal cancer $(24.1 \%)$ (Table 1$)$.

93 patients (42.3\%) were found to use at least one CAM method (Fig. 1). The most common CAM method was

Table 1. Sociodemographic and disease characteristics of the patients enrolled in the study

\begin{tabular}{|c|c|}
\hline & Mean \pm SD (min. $-\max )$. \\
\hline Age & $56.5 \pm 12.2(24-83)$ \\
\hline \multicolumn{2}{|l|}{ Gender [N (\%)] } \\
\hline Male & 79 (35.9) \\
\hline Female & $141(64.1)$ \\
\hline \multicolumn{2}{|c|}{ Marriage status [N (\%)] } \\
\hline Single & $9(4.1)$ \\
\hline Married & $181(82.3)$ \\
\hline Widow & $30(13.6)$ \\
\hline \multicolumn{2}{|c|}{ Educational status [N (\%)] } \\
\hline Illiterate & $15(6.8)$ \\
\hline Primary school & $72(32.7)$ \\
\hline Middle school & $22(10)$ \\
\hline High school & $67(37.5)$ \\
\hline Higher education & $44(20)$ \\
\hline \multicolumn{2}{|c|}{ Cancer diagnoses [N (\%)] } \\
\hline Breast & 79 (35.9) \\
\hline Colon-Rectum & $53(24.1)$ \\
\hline Ovary & $15(6.8)$ \\
\hline Stomach & $14(6.4)$ \\
\hline Lung & $13(5.9)$ \\
\hline Pancreas & $9(4.1)$ \\
\hline Other & $37(16.8)$ \\
\hline
\end{tabular}

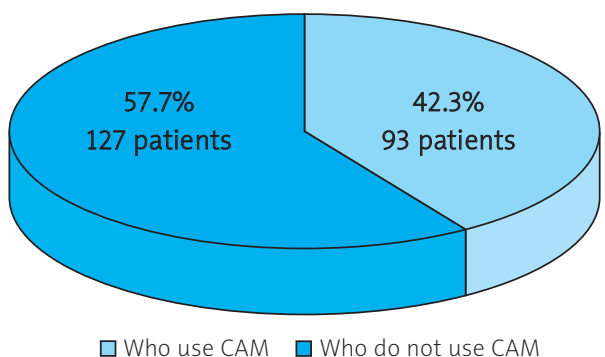

Fig. 1. The complementary alternative medicine usage ratios in our population under survey herbal therapy followed by supportive treatment. The number of patients using herbal therapy was 81 (36.8\%). As supportive treatment, the commonly preferred honey and pollen were detected to be mainly used together with nettle seed. Patients using and not using CAM were compared with respect to Beck Depression, STAI anxiety and Beck Hopelessness scores. No statistically significant difference was detected between the groups in BDI $(12.0 \pm 8.4,11.9 \pm 8.7$, $p=0.96)$, BHS $(5.5 \pm 4.9,4.8 \pm 4.4, p=0.27)$ or STAI $(43.7 \pm 8.0$, $44.3 \pm 8.2, p=0.64$ ) scores (Table 2 ).

Patients using and not using CAM were compared with respect to WHOQOL-BREF quality of life scores. There was no statistically significant difference between the groups in WHOQOL-BREF sub-group scores (physical, psychological, social relations, environment, standardized by culture (environment, general health) (Table 3).

\section{Discussion}

The Beck Depression Inventory performed to determine the severity of depression symptoms revealed a low severity of depressive symptoms for patients. No significant difference was detected between the groups using and not using CAM. In addition, the low mean BDI score (measuring the desperation status) detected in those using and not using CAM showed that our patients had a low level of desperation overall. Our trial indicated that the level of desperation and depression was not high in general. The results of both scales were found to be consistent in this respect. A trial by Montazeri et al. showed that CAM use was associated with severe depression while it was not associated with quality of life or anxiety in patients with breast cancer [26]. Our results may demonstrate that patients presenting to a university hospital receive the necessary support services and cling on to life more strongly. The fact that patients enrolled were using chemotherapy and a new treatment or adjuvant therapy is a new hope for patients and a target as the determination of clinging onto life more strongly and overcoming the disease may have contributed to the low level of hopelessness and depression observed in patients. What determines the desperation and depression level may be the unfavourable course (recurrence and extent) of the disease. This may be separately investigated in another trial.

There was no statistically significant difference between the two groups with respect to the STAI scores measuring the anxiety level of our patients. The fact that the mean scores were not that high suggested that patients were favourably good with respect to anxiety. A trial conducted

Table 2. Psychological status by CAM use

$\begin{array}{lcc} & \text { Using CAM } & \text { Not using CAM } \\ \text { Mean } \pm \text { SD } & \text { Mean } \pm \text { SD } & 11.9 \pm 8.7 \\ \text { Beck Depression Inventory } & 12.0 \pm 8.4 & n=125 \\ \text { score } & n=91 & 44.3 \pm 8.2 \\ \text { State-Trait Anxiety Inventory } & 43.7 \pm 8.0 & n=125 \\ \text { score } & n=93 & 4.8 \pm 4.4 \\ \text { Beck Hopelessness } & 5.5 \pm 4.9 & n=123 \\ \text { Scale score } & n=91 & 0.27\end{array}$

t test $P<0.05$ significant 
Table 3. WHOQOL-BREF quality of life by use of CAM

\begin{tabular}{|lcc}
\hline $\begin{array}{l}\text { Fields associated with } \\
\text { quality of life }\end{array}$ & $\begin{array}{c}\text { Using CAM Mean } \pm \text { SD } \\
(n=90)\end{array}$ & $\begin{array}{c}\text { Not using CAM Mean } \pm \text { SD } \\
(n=122)\end{array}$ \\
\hline Physical & $61.5 \pm 21.0$ & $61.6 \pm 19.7$ \\
\hline Psychological & $70.0 \pm 13.9$ & $66.1 \pm 17.8$ \\
\hline Social & $64.3 \pm 16.2$ & $63.4 \pm 21.2$ \\
\hline Environmental & $69.8 \pm 12.6$ & $70.2 \pm 14.4$ \\
\hline Standardized by culture (environment) & $68.8 \pm 11.6$ & $69.5 \pm 13.0$ \\
\hline General health & $6.6 \pm 1.6$ & $6.7 \pm 1.7$ \\
\hline
\end{tabular}

t test $P<0.05$ significant

in normal adults revealed a mean STAI score of 40.03 [27]. A trial conducted in oncology patients revealed a mean score of $45.4 \pm 5.5$. Our results were slightly lower than those of Balım et al. [27] (43.7 \pm 8.0$)$ in those receiving CAM and 44.3 \pm 8.2 in those not receiving CAM. Anxiety is a subjective fear resulting from the stress condition the individual is in. Uncertainty of the disease course and treatment, and deficiency in informing the patient are important factors that increase the state of anxiety [27]. In this respect, patients may be considered to have received adequate information and a necessary level of psychological support; they may have a low level of uncertainty regarding the future and this may have reduced anxiety. To better understand this situation, studies are required to compare the status of patients at state hospitals and Social Security Institution hospitals with those at university hospitals. One of the reasons for anxiety is depression. The low BDI scores of our patients are consistent with the scores obtained from STAl in this respect.

There was no statistically significant difference between the two groups with respect to the quality of life scores measured using WHO-BREF. Armstrong et al. reported no difference in quality of life in patients with brain tumours using and not using CAM [28]. In the study by Hlubocky et al., the quality of life was detected to be worse in the group using CAM [29]. With respect to the effect on quality of life, and the high psychological scores detected in those using CAM, even if not to a significant level ( $p=0.07)$, CAM may be considered to increase quality of life in psychological respects.

A larger and better-arranged study may investigate the patients in these respects at certain intervals and compare the scores obtained in the period where there is a tendency towards CAM, with the previous scores and the scores of the patients who do not use CAM, and detect how these scores changed with CAM.

In conclusion, CAM use was determined not to be significantly related to anxiety, depression or quality of life of patients. Actually, these scales measure the psycho-social status and quality of life of patients within a certain period of time (limited to the last few weeks). Therefore, our study is deficient in this respect. This study evaluates the status of patients within a certain period of time.

\section{References}

1. Panel on Definition and Description. Defining and Describing Complementary and Alternative Medicine. CAM Research Methodology Conference, April 1995. Altern Ther 1997; 3: 49.

2. Hyodo I, Eguchi K, Nishina T, Endo H, Tanimizu M, Mikami I, Takashima S, Imanishi J. Perceptions and attitudes of clinical oncologists on complementary and alternative medicine: a nationwide survey in Japan. Cancer 2003; 97: 2861-8.

3. Burstein HJ, Gelber S, Guadagnoli E, Weeks JC. Use of alternative medicine by women with early-stage breast cancer. N Engl J Med 1999; 340: 1733-9.

4. Astin JA. Why patients use alternative medicine results of a national study. JAMA 1998; 279: 1548-53.

5. Lerner IJ. The whys of cancer quackery. Cancer 1981; 53: 815-9.

6. Danielson KJ, Stewart DE, Lipper GP. Unconventional cancer remedies. CMAJ 1998; 339: 839-41.

7. Cassileth BR, Chapman CC. Alternative and complementary cancer therapies. Cancer 1996; 77: 1026-34.

8. Angell M, Kassier JP. Alternative medicine-the risk of untested and unregulated remedies. N Engl J Med 1998; 339: 839-41.

9. Ernst E, Willoughby M, Weihmayr TH. Nine Possible reasons for choosing complementary medicine. Perfusion 1995; 11: 356-8.

10. Grothey A, Duppe J, Hasenburg A, Voigtmann R. Use of alternative medicine in oncology patients. Dtsch Med Wochenschr 1998; 123: 923-9.

11. Samur M, Bozcuk HS, Kara A, Sava B. Factors associated with utilization of nonproven cancer therapies in Turkey A study of 135 patients from a single center. Support Care Cancer 2001; 9: 452-8.

12. Lerner IJ, Kennedy BJ. The prevalence of questionable methods of cancer treatment in the United States. CA Cancer J Clin 1992; 42: 181-91.

13. Risberg T, Lund E, Wist E, Dahl O, Sundstrøm S, Andersen OK, Kaasa S. The use of non-proven therapy among patients treated in Norwegian oncological departments. A cross-sectional national multicentre study. Eur J Cancer 1995; 31: 1785-9.

14. Ernst E, Cassileth BR. The prevalence of complementary/alternative medicine in cancer: a systematic review. Cancer 1998; 83: 777-82.

15. Cetingoz R, Tanrı̈̈ver Y, Ataman ÖU, Kınay M. Kanser hastalarında tıp dıșı tedavi yöntemlerinin araștırılmas. Dokuz Eylül Üniversitesi Tıp Fakültesi Dergisi 2000; 14: 245-9.

16. Ceylan S, Hamzaoğlu O, Kömürcü S, Beyan C, Yalçın A. Survey of the use of comlementary and alternative medicine among Turkish cancer patients. Complement Ther Med 2002; 10: 94-9.

17. Gozum S, Tezel A, Koç M. Comlementary and alternative treatments used by patients with cancer in eastern Turkey. Cancer Nurs 2003; 26: 230-6.

18. Holland JC. Why patients seek unproven cancer remedies: a psychological perspective. CA Cancer J Clin 1982; 32: 10-4.

19. Verhoef MJ, Hagen N, Pelletier G, Forsyth P. Alternative therapy use in neurologic diseases: use in brain tumor patients. Neurology 1999; 52: $617-22$ 
20. Öner N. Türkiye'de Kullan lan Psikolojik Testler: Bir Bașvuru Kaynağı Boğaziçi Üniversitesi Yayınları. Istanbul 1996.

21. Savasir I, Sahin NH. Bilișsel-Davranșçı Terapilerde Değerlendirme: Sık Kullanılan Ölçekler. Türk Psikologlar Derne i Yayınları, Ankara 1997.

22. Seber G. Beck Umutsuzluk Ölçeğinin Geçerliliği ve Güvenilirliği Üzerine Bir Çağșma. Yayınlanmamıș Doçentlik Tezi Anadolu Üniversitesi Tıp Fakültesi Psikiyatri Bölümü, Eskișehir 1991.

23. Aslan H, Soylu M, Alparslan N, Ünal M. Behçet Hastalığında Psikososyal Etkenler ve Ruhsal Bulgular. Türk Psikiyatri dergisi 1996; 7: 215-21.

24. The WHOQOL Group: Development of the World Health Organization WHOQL-BREF Quality of Life Assessment Phsychological Medicine 1998; 28: 551-8.

25. Fidaner H, Elbi H, Fidaner C, Eser SY, Eser E, Göker E. WHOQOL100 ve WHOQOL-BREF'in Psikometrik Özellikleri, Psikiyatri Psikoloji Psikofarmakoloji Dergisi 1999; 7: 23-40.

26. Montazeri A, Sajadian A, Ebrahimi M, Akbari ME. Depression and the use of complementary medicine among breast cancer patients Support Care Cancer 2005; 13: 339-42.

27. Balım E, Dilbaz N, Bayam G, Holat H, Tosun E, Esen M. Medikal. Onkoloji Hastalarında Depresyon Kaygı, Ümitsizlik Düzeylerinin Değerlendirilmesi Konsültasyon-Liyezon Psikiyatrisi Kitabı, IV. Konsültasyon - Liyezon Psikiyatrisi Kongresi 1996; 1: 235-41.

28. Armstrong T, Cohen MZ, Hess KR, et al. Complementary and alternative medicine use and quality of life in patients with primary brain tumors. J Pain Symptom Manage 2006; 32: 148-54.

29. Hlubocky FJ, Ratain MJ, Wen M, Daugherty CK. Complementary and alternative medicine among advanced cancer patients enrolled on phase I trials: a study of prognosis, quality of life, and preferences for decision making.J Clin Oncol 2007; 25: 548-4.

\section{Address for correspondence}

Ahmet Alacacioglu MD

Izmir Training and Research Hospital

Medical Oncology, Izmir, Turkey

tel. +90 2322505050

e-mail: dralacacioglu@hotmail.com 